\title{
Efficiency Investigations of a 3 kW T-Type Inverter for Switching Frequencies up to 100
} $\mathbf{k H z}$

Anthon, Alexander; Zhang, Zhe; Andersen, Michael A. E.; Franke, Toke

Published in:

Proceedings of the 2014 International Power Electronics Conference

Link to article, DOI:

10.1109/IPEC.2014.6869562

Publication date:

2014

Document Version

Peer reviewed version

Link back to DTU Orbit

Citation (APA):

Anthon, A., Zhang, Z., Andersen, M. A. E., \& Franke, T. (2014). Efficiency Investigations of a 3 kW T-Type Inverter for Switching Frequencies up to $100 \mathrm{kHz}$. In Proceedings of the 2014 International Power Electronics Conference (pp. 78-83). IEEE. https://doi.org/10.1109/IPEC.2014.6869562

\section{General rights}

Copyright and moral rights for the publications made accessible in the public portal are retained by the authors and/or other copyright owners and it is a condition of accessing publications that users recognise and abide by the legal requirements associated with these rights.

- Users may download and print one copy of any publication from the public portal for the purpose of private study or research.

- You may not further distribute the material or use it for any profit-making activity or commercial gain

- You may freely distribute the URL identifying the publication in the public portal 


\title{
Efficiency Investigations of a $3 \mathrm{~kW}$ T-Type Inverter for Switching Frequencies up to $100 \mathrm{kHz}$
}

\author{
Alexander Anthon, Zhe Zhang, Michael A.E. Andersen \\ Dept. of Electrical Engineering \\ Technical University of Denmark \\ Kgs. Lyngby, Denmark \\ jant@elektro.dtu.dk
}

\begin{abstract}
This paper deals with a $3 \mathrm{~kW}$ multilevel inverter used for PV applications. A comparison has been made based on simulations using IGBTs and SiC MOSFETs to see how much efficiency can be gained when $\mathrm{SiC}$ diodes are used. A prototype with the same IGBTs and $\mathrm{SiC}$ MOSFETs has been built but using regular soft-recovery $\mathrm{Si}$ diodes instead of $\mathrm{SiC}$ diodes. Efficiencies and switching transitions for different switching frequencies up to $100 \mathrm{kHz}$ have been measured. Thermal investigations of both IGBTs and SiC MOSFETs have been conducted to analyze the feasibility of increased switching frequencies. When $\mathrm{SiC}$ MOSFETs are used in combination with Si diodes, switching frequencies could be doubled achieving the same efficiencies than the IGBT converter.
\end{abstract}

Keywords-SiC MOSFET, IGBT, multilevel inverter, reverse recovery current

\section{INTRODUCTION}

Photovoltaic (PV) systems have become more and more attractive in recent years. Especially residential PV inverter systems gained much attraction. Due to the low efficiency of the PV panels themselves, much attention must be paid in the design of the PV inverter which leads to a strong demand for low cost and high efficiency power converters. Two-level inverters have the advantage of having a lower cost factor due to the smaller amount of components, being simple in structure and control but suffer from a strong switching frequency and power depending efficiency as well as a relatively large output filter [1]. Multilevel topologies such as the Neutral-Point-Clamped (NPC) inverter have, on the other hand, efficiencies which are less depending on the switching frequency and they give a good compromise between system complexity, cost and efficiency [2]-[3]. Among the three-level inverter topologies, the T-Type inverter (also called Conergy [4] or BSNPC [5]) shows a higher efficiency than the NPC counterpart for low to medium switching frequencies [3]. Furthermore, the efficiency of the T-Type inverter can be improved by using Silicon Carbide ( $\mathrm{SiC}$ ) switching devices in order to reduce switching losses by increased switching transitions and hence increase the overall efficiency. Previous work has shown that $\mathrm{SiC}$ switching devices such as normally-on/off SiC JFETs, SiC BJTs and SiC MOSFETs show superior switching performance in various applications over their

\author{
Dr.-Ing. Toke Franke \\ Danfoss Silicon Power \\ Flensburg, Germany
}

silicon counterparts, [6]-[7]. An all SiC MOSFET T-Type inverter has been introduced in [8] achieving efficiencies over $98 \%$. A major aspect when using fast switching $\mathrm{SiC}$ devices is to equip the converter with $\mathrm{SiC}$ diodes instead of $\mathrm{Si}$ diodes in order to keep the switching losses low; otherwise the reverse recovery current caused by a high di/dt will increase the switching losses again and hence dampen the efficiency improvements. The feasibility of using $\mathrm{SiC}$ MOSFETs in the T-Type converter is investigated on a practical approach in this paper. Two $3 \mathrm{~kW}$ T-Type inverters equipped with $1200 \mathrm{~V}$ IGBTs and $1200 \mathrm{~V}$ SiC MOSFETs are compared for different power levels and switching frequencies. In Section II the topology including its modulation and current commutation is explained. Simulations of the topology have been carried out in Section III, in which expected efficiencies are obtained and a breakdown loss analysis is conducted. Practical results and efficiency measurements of a $3 \mathrm{~kW}$ prototype are introduced in section Section IV. Efficiency investigations for increased switching frequencies are investigated in Section V.

\section{THE T-TYPE INVERTER}

The T-Type inverter is a derivation from the NPC inverter. One phase leg comprises of four switching devices and four diodes as shown in Fig. 1. The output voltage of the inverter has three states with reference to the midpoint $\mathrm{M}$, i.e. $+0.5 V_{D C}, 0$ and $-0.5 V_{D C}$. It is a commonly used topology in three-phase PV inverters in the medium power range and rather low switching frequencies of up to $16 \mathrm{kHz}$. Switches $S_{1}$ and $S_{3}$ including their free-wheeling diodes $D_{3}$ and $D_{4}$ require a breakdown voltage of at least the full DC link voltage $V_{D C}$ whereas switches $S_{3}, S_{4}$ and the diodes $D_{1}$ and $D_{2}$ require a breakdown voltage of at least half the DC link voltage. In PV inverter systems, the DC link voltage can usually increase up to $1000 \mathrm{~V}$, so $S_{1}, S_{2}, D_{3}$ and $D_{4}$ are $1200 \mathrm{~V}$ and $S_{3}, S_{4}, D_{1}$ and $D_{2}$ are $600 \mathrm{~V}$ devices to have a margin for overvoltages. A sinusoidal output voltage can be obtained by having switches $S_{1}$ and $S_{2}$ operated at a chosen switching frequency whereas switches $S_{3}$ and $S_{4}$ operate at grid frequency as shown in Fig. 1. The T-Type topology benefits from having lower conduction losses than its NPC counterpart because only 


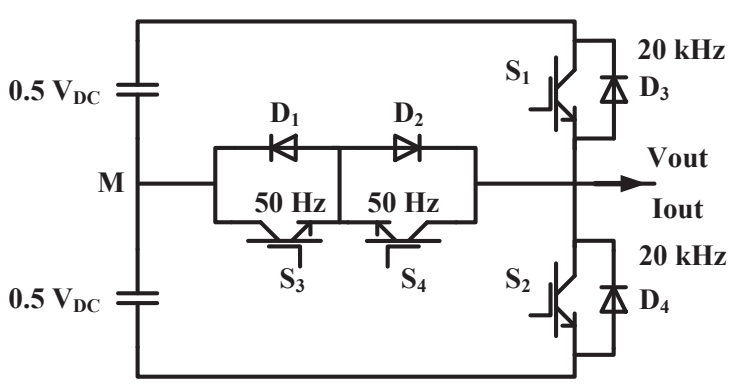

(a) Schematic of a single phase T-Type inverter with midpoint connection

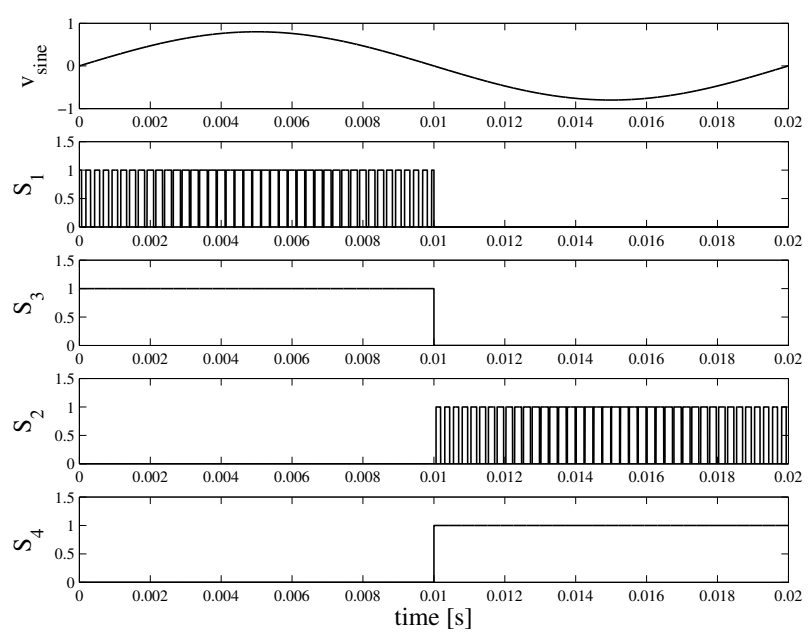

(b) Output voltage creation of the T-Type inverter using sinusoidal PWM

Fig. 1. Schematic of a single phase T-Type inverter and sinusoidal PWM scheme

TABLE I. SPECIFICATIONS

\begin{tabular}{ccc}
\hline Symbol & Meaning & Value \\
\hline$L$ & Output filter inductance & $3 \mathrm{mH}$ \\
$V_{D C}$ & DC link voltage & $800 \mathrm{~V}$ \\
$V_{\text {out }}$ & Filtered output voltage, RMS & $230 \mathrm{~V}$ \\
$P_{\text {out }}$ & Output power & $250 \mathrm{~W}$ to $3000 \mathrm{~W}$ \\
\hline
\end{tabular}

one switch conducts current at the same time. The current commutations for a resistive load are shown in Fig. 2.

\section{Simulation Results With SiC Diodes}

The simulations were done in PLECS and the semiconductor parameters were taken from their datasheets. The specifications for the inverter are shown in Table I. Switches $S_{1}$ and $S_{2}$ are chosen to be IGBTs due to their higher breakdown capabilities compared to Si MOSFETs. Their SiC counterpart will be a $1200 \mathrm{~V}$ SiC MOSFET C2M0080120D from Cree. Switches $S_{3}$ and $S_{4}$ are chosen to be IGBTs in both configurations due to their low switching frequency requirements. The diodes $D_{1}$ and $D_{2}$ are $\mathrm{SiC}$ diodes to show possible achievable efficiencies when no reverse recovery is taken into account. Table II shows the semiconductors used in the simulations. The $\mathrm{Si}$ converter comprises of $1200 \mathrm{~V}$ IGBTs and the SiC converter comprises of $1200 \mathrm{~V} \mathrm{SiC}$ MOSFETs.

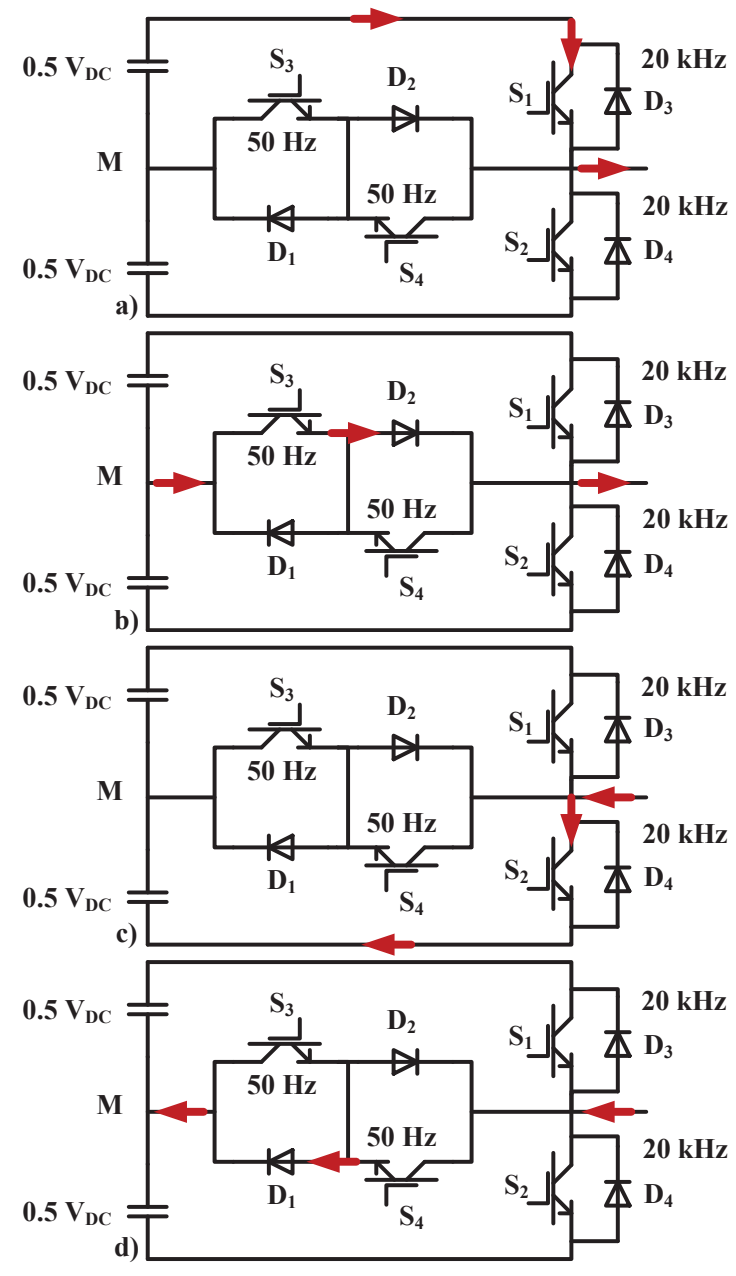

Fig. 2. Current paths in the T-Type inverter. a) Positive output voltage b) Zero output voltage c) Negative output voltage d) Zero output voltage

TABLE II. SEMICONDUCTORS

\begin{tabular}{cccc}
\hline Version & $D_{1}$ and $D_{2}$ & $S_{1}$ and $S_{2}$ & $S_{3}$ and $S_{4}$ \\
\hline Si Converter & C4D20120A & IKW15N120T2 & IKP15N60T \\
SiC Converter & C4D20120A & C2M0080120D & IKP15N60T \\
\hline
\end{tabular}

The simulation results of the T-Type inverter for $16 \mathrm{kHz}$ and $30 \mathrm{kHz}$ are shown in Fig. 3. At a switching frequency of $16 \mathrm{kHz}$, a maximum efficiency of $97.9 \%$ is achieved when IGBTs are used and $98.6 \%$ when $\mathrm{SiC}$ MOSFETs are used. A larger efficiency difference between the IGBT version and SiC MOSFET version can be obtained if the switching frequency is increased to $30 \mathrm{kHz}$. Then a maximum efficiency of $97 \%$ with IGBTs and $98.2 \%$ with SiC MOSFETs are achieved. Although the specifications do not exactly match with [8], the results are close to what has been presented in previous work so that the simulations can be considered a proper representation of what to expect. A breakdown loss analysis has been conducted to show the loss distribution of the converter system. Apart from the semiconductors, losses in the filter inductor as well as the DC link capacitors have been included. The results are shown in Fig. 3. It can be seen that due to the modulation applied, switching losses mainly occur in the $1200 \mathrm{~V}$ switches. 


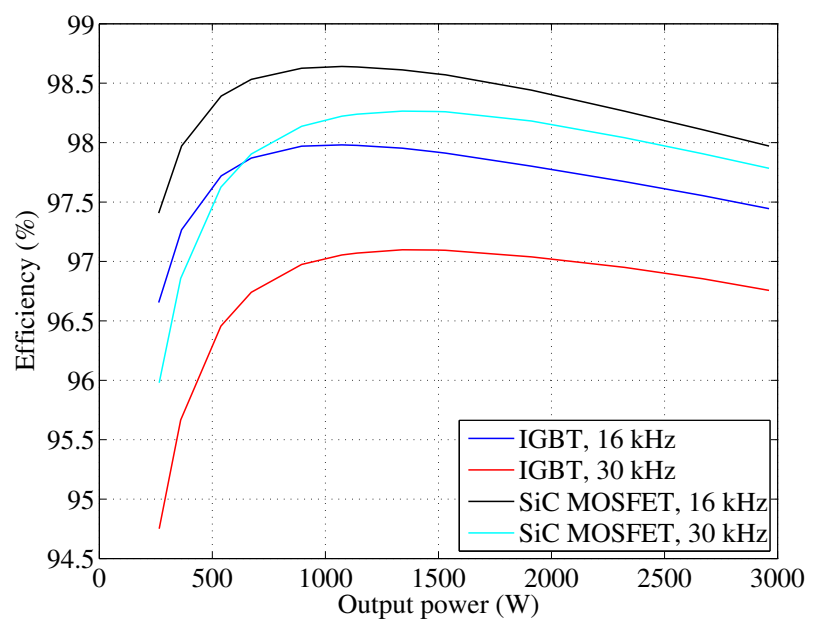

(a) Simulation results of T-Type inverter using $1200 \mathrm{~V}$ IGBTs with $R_{g}=2.2 \Omega$ and $1200 \mathrm{~V} \mathrm{SiC} \mathrm{MOSFETs} \mathrm{with} R_{g}=5 \Omega$

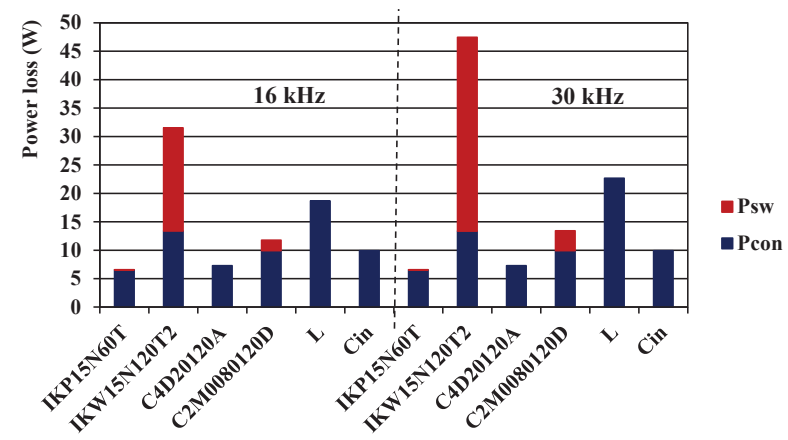

(b) Breakdown analysis of loss distribution in the T-Type inverter at a full power of $3 \mathrm{~kW}$

Fig. 3. Simulation results of T-Type inverter using $1200 \mathrm{~V}$ IGBTs and 1200 V SiC MOSFETs

Hence the switching frequency is a limiting factor for the efficiency of the T-Type inverter. However, switching losses can be reduced by using $\mathrm{SiC}$ switching devices. The effect of the fast switching capabilities of SiC devices becomes more important when a higher power density is targeted because switching losses in regular IGBTs become dominant degrading overall efficiency. Based on the simulations, switching and conduction losses in the $1200 \mathrm{~V}$ IGBT are relatively balanced at a switching frequency of $16 \mathrm{kHz}$ whereas switching losses of the $\mathrm{SiC}$ MOSFETs are still smaller than the conduction losses at a switching frequency of $30 \mathrm{kHz}$. Both the size of the filter inductor and the DC link capacitors were kept constant, though a redesign of these could have reduced losses at increased switching frequencies. However, a main requirement to the simulated efficiencies is that the diodes $D_{1}$ and $D_{2}$ do not show any reverse recovery current.

\section{EXPERIMENTAL RESULTS}

To see how the T-Type inverter performs with IGBTs and SiC MOSFETs, a prototype has been built which is shown in Fig. 4. For both the $1200 \mathrm{~V}$ IGBTs and SiC MOSFETs, a TO-247 package was used having the same pinning and hence the same printed circuit board

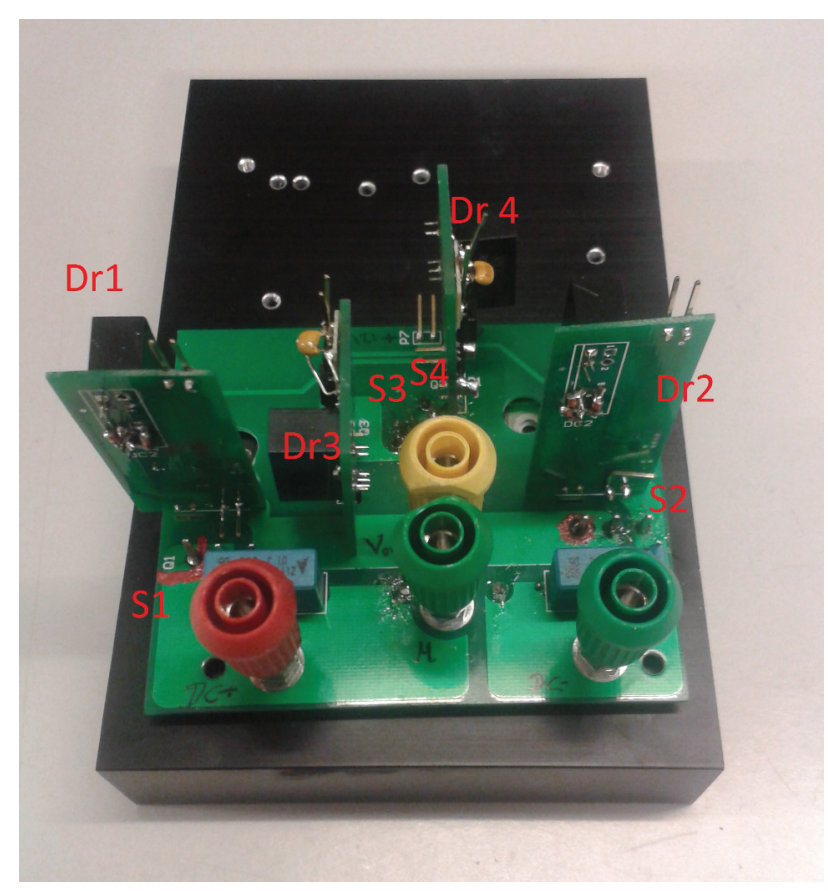

Fig. 4. Prototype of a $3 \mathrm{~kW}$ T-Type inverter. The dimensions of the printed circuit board are $8.5 \mathrm{~cm}$ by $7 \mathrm{~cm}$

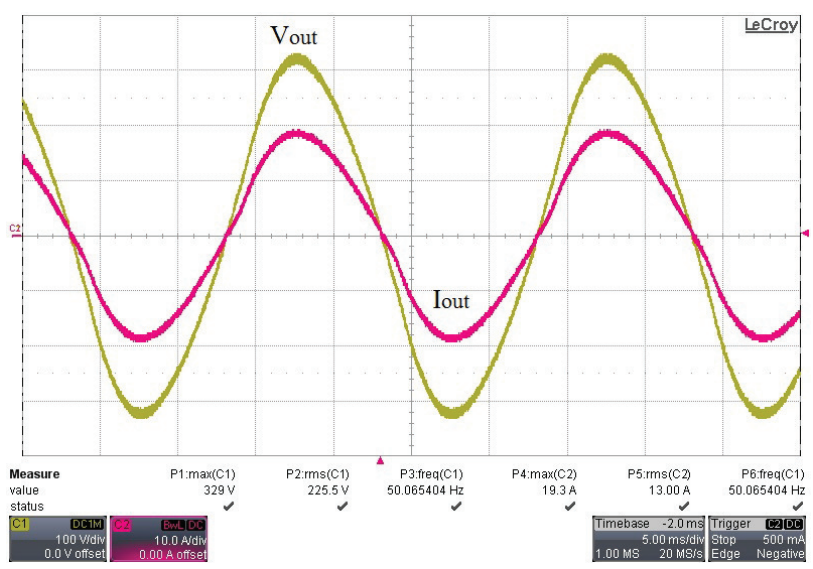

Fig. 5. Filtered output waveforms at an output power of $3 \mathrm{~kW}$ and a switching frequency of $16 \mathrm{kHz}$

(PCB) and layout could be used for a fair comparison. For layout optimization, $S_{3}$ and $D_{1}$ are packed in one TO-220 package and so are $S_{4}$ and $D_{2}$. Hence the whole converter could be built with four discrete devices. Only the gate drivers (Dr1 - Dr4) for the IGBTs and SiC MOSFETs were adjusted to stay within their absolute maximum ratings for the Gate-Source voltage. The IGBTs were switched on and off with a Gate-Source voltage of $\pm 15 \mathrm{~V}$ whereas the SiC MOSFETs were switched on with a Gate-Source voltage of $19 \mathrm{~V}$ and switched off with a Gate-Source voltage of $-5 \mathrm{~V}$. For further comparisons to the simulations, the prototype is equipped with soft-recovery $\mathrm{Si}$ diodes instead of $\mathrm{SiC}$ diodes. At full power, the filtered output voltage and current are shown in Fig. 5.

A N4L PPA5500 power analyzer was used for efficiency measurements. A first comparison is made with 
an IGBT version having a gate resistance of $2.2 \Omega$ and a SiC MOSFET version having a gate resistance of $5 \Omega$. The results are shown in Fig. 6.

It can be seen in Fig. 6 that the efficiency could be improved when a SiC MOSFET with a gate resistance of $5 \Omega$ is implemented. However, efficiency improvements are larger as the switching frequency is increased. At $16 \mathrm{kHz}$, a maximum efficiency improvement of $0.3 \%$ is achieved. Increasing switching frequency to $30 \mathrm{kHz}$ leads to a maximum efficiency improvement of $0.8 \%$. It can furthermore be seen that the SiC MOSFET inverter has similar efficiencies at $30 \mathrm{kHz}$ than the IGBT inverter at $16 \mathrm{kHz}$. The switching frequency for the SiC converter is therefore increased to $60 \mathrm{kHz}$ and plotted in Fig. 6. It can be seen that the $\mathrm{SiC}$ converter at $60 \mathrm{kHz}$ has similar efficiencies than the IGBT converter at $30 \mathrm{kHz}$ which yields to the conclusion that the switching frequency can be doubled when SiC MOSFETs are implemented without degrading the efficiency. The case temperatures of the IGBTs and SiC MOSFETs were measured to get a comparison of the power dissipation in such devices. The operating conditions are at full power, i.e. $3 \mathrm{~kW}$ and $20 \mathrm{kHz}$ for the IGBT and $30 \mathrm{kHz}$ for the SiC MOSFET. The case temperatures were measured with an infrared camera and the results are shown in Fig. 7.

It is seen in Fig. 7 that even though the switching frequency is increased, the case temperature for the $\mathrm{SiC}$ MOSFET is around $10^{\circ} \mathrm{C}$ lower. The thermal resistance of the $1200 \mathrm{~V}$ IGBT is given in the datasheet to be $0.63 \mathrm{~K} / \mathrm{W}$ and the thermal resistance for the SiC MOSFET is given to be $0.60 \mathrm{~K} / \mathrm{W}$. Hence the junction temperature of the $\mathrm{SiC}$ MOSFET is around $10^{\circ} \mathrm{C}$ lower as well. That the case temperature of the $600 \mathrm{~V}$ IGBT is higher than the case temperature of the SiC MOSFET can be explained by the fact that a regular TO-220 package for the IGBT was used. In that package, the IGBT comes along with a Si soft recovery free-wheeling diode. These free-wheeling diodes for the two $600 \mathrm{~V}$ IGBTs are used to be $D_{1}$ and $D_{2}$. As a consequence, the TO-220 package withstands the power dissipation for both the

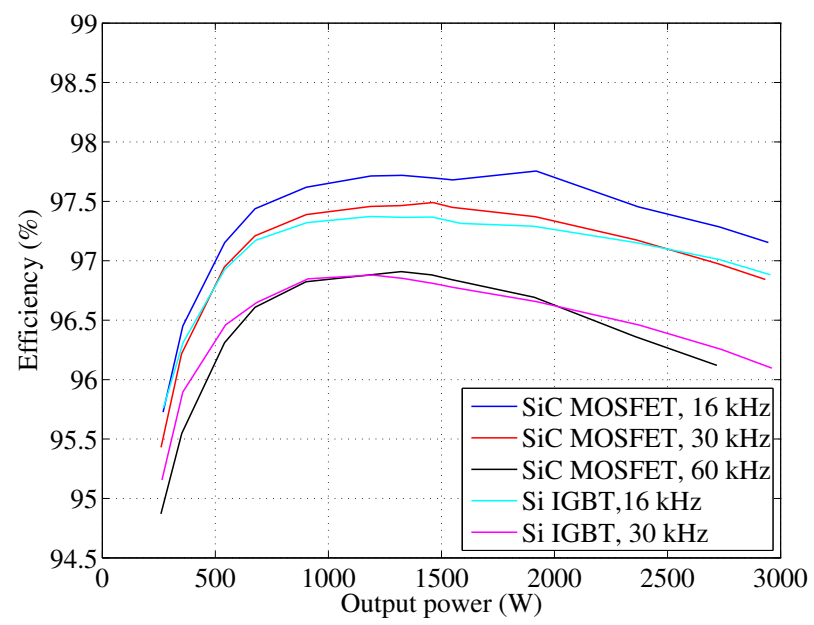

Fig. 6. Measured efficiencies of IGBT and SiC T-Type inverter at different switching frequencies

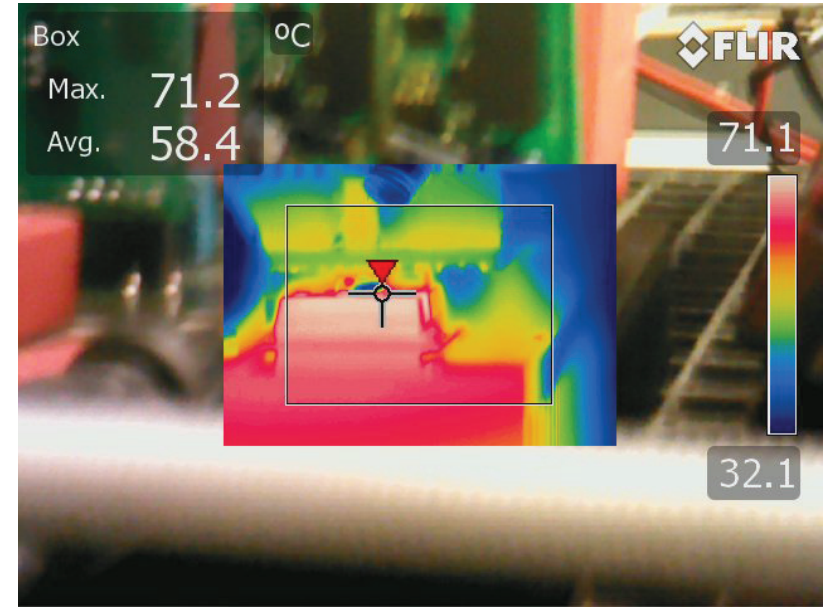

(a) Case temperature of IGBT at $20 \mathrm{kHz}$ and $3 \mathrm{~kW}$

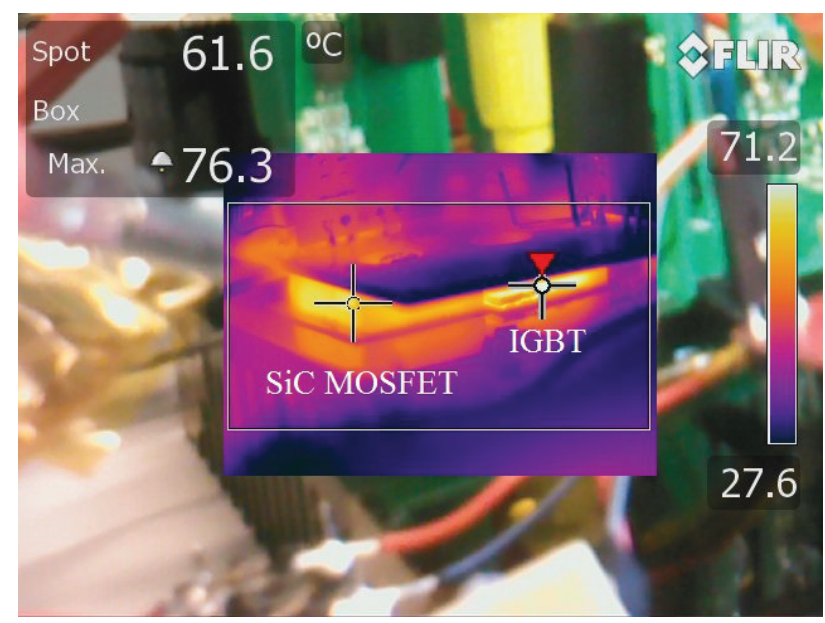

(b) Case temperatures of $\mathrm{SiC}$ MOSFET and $600 \mathrm{~V}$ IGBT+Diode at $30 \mathrm{kHz}$ and $3 \mathrm{~kW}$

Fig. 7. Temperature measurements of $1200 \mathrm{~V}$ switching devices

IGBT and the free-wheeling diode. A switching transition for both turn on and turn off of the SiC MOSFET has been captured. The gate resistance is kept to be $5 \Omega$, output power is $900 \mathrm{~W}$ and switching frequency is $16 \mathrm{kHz}$. The current was measured with a Rogowski coil having a $20 \mathrm{MHz}$ bandwidth limitation. The Drain-Source voltage was measured with a high voltage probe with a $400 \mathrm{MHz}$ bandwidth limitation and the Gate-Source voltage was measured with a voltage probe having a $500 \mathrm{MHz}$ bandwidth limitation. Furthermore, the time delay of $24 \mathrm{~ns}$ of the Rogowski coil was compensated in the measurements and the attenuation for the current measurement was set such that $2 \mathrm{~V} / \mathrm{div}$ equals to $2 \mathrm{~A} / \mathrm{div}$. The transitions are shown in Fig. 8. It can be seen in Fig. 8a that the SiC MOSFET switches $400 \mathrm{~V}$ within 30ns resulting in a dv/dt of more than $13 \mathrm{kV} / \mu \mathrm{s}$. A maximum $\mathrm{dv} / \mathrm{dt}$ was measured to be $25 \mathrm{kV} / \mu \mathrm{s}$. The current rises $2 \mathrm{~A}$ within $4 \mathrm{~ns}$ resulting in a di/dt of $500 \mathrm{~A} / \mu \mathrm{s}$. The peak current is measured to be $10 \mathrm{~A}$. During the turn off transition as shown in Fig. $8 b$, the maximum $d v / d t$ is measured to be $20 \mathrm{kV} / \mu \mathrm{s}$. The maximum di/dt is $400 \mathrm{~A} / \mu \mathrm{s}$. For comparison, the IGBT switched $400 \mathrm{~V}$ within $120 \mathrm{~ns}$ resulting in a dv/dt of $3 \mathrm{kV} / \mu \mathrm{s}$. 


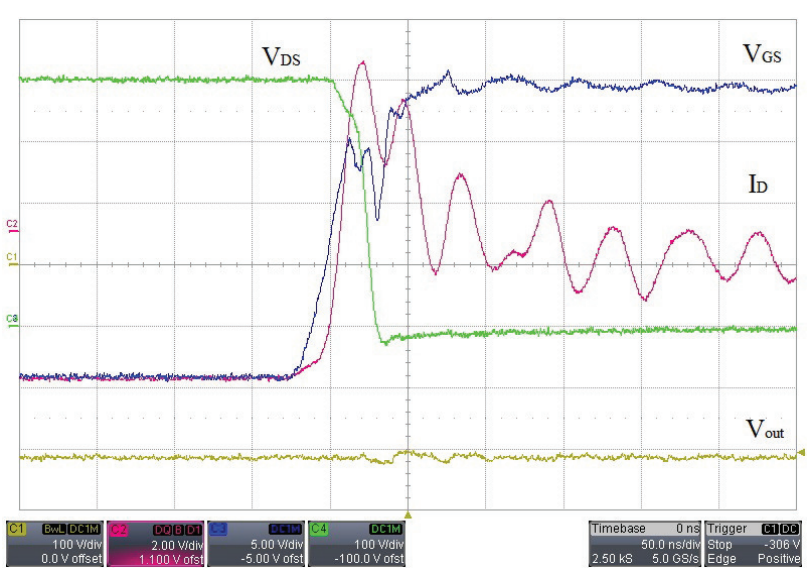

(a) Turn on transition

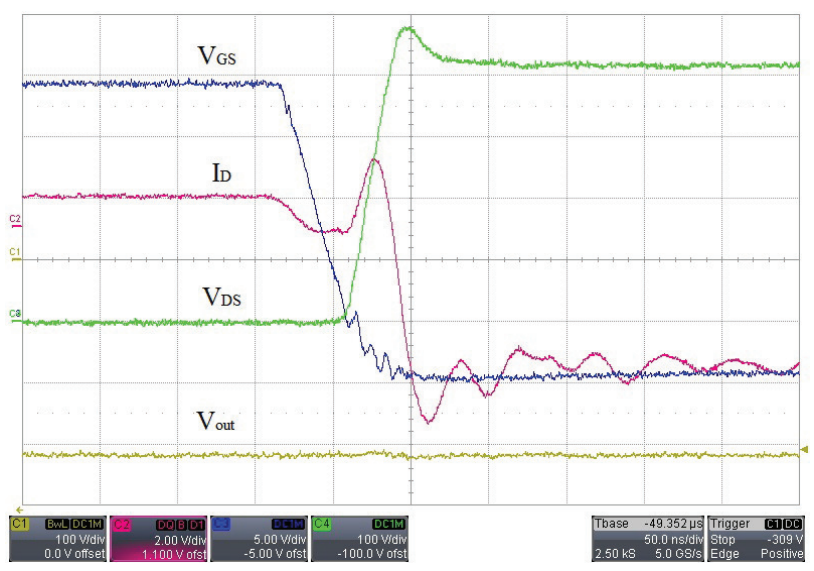

(b) Turn off transition

Fig. 8. Turn on and turn off transition of SiC MOSFET

\section{EFFICIENCY INVESTIGATIONS FOR INCREASED SWITCHING FREQUENCIES}

It is seen that the efficiencies could be improved when SiC MOSFETs are implemented and the switching frequency could be doubled achieving the same efficiencies when IGBTs are used. It is therefore of interest to furthermore increase the switching frequency and to see how it affects the efficiency. As a last operating point, the switching frequency is increased to $100 \mathrm{kHz}$. The efficiency curves for the SiC converter at different switching frequencies are shown in Fig. 9.

It can be seen that the overall efficiency dramatically drops as the switching frequency increases up to $100 \mathrm{kHz}$. Also, the maximum efficiency point is shifted down to a lower power operating point compared to lower switching frequencies. The measurements were limited to a maximum power of $1.6 \mathrm{~kW}$ as the case temperature of the TO-220 packages became too high and hence the risk of a thermal damage was increased. However, the case temperature of the SiC MOSFETs were still below $80^{\circ} \mathrm{C}$ at an output power of $1.6 \mathrm{~kW}$. So the limiting factor are the $600 \mathrm{~V}$ devices in the TO-220 package. A thermal picture of the TO-220 package at an operating point of $60 \mathrm{kHz}$ and $2.7 \mathrm{~kW}$ was taken to verify the limiting factor at increased switching frequencies. The result is shown in Fig. 10.

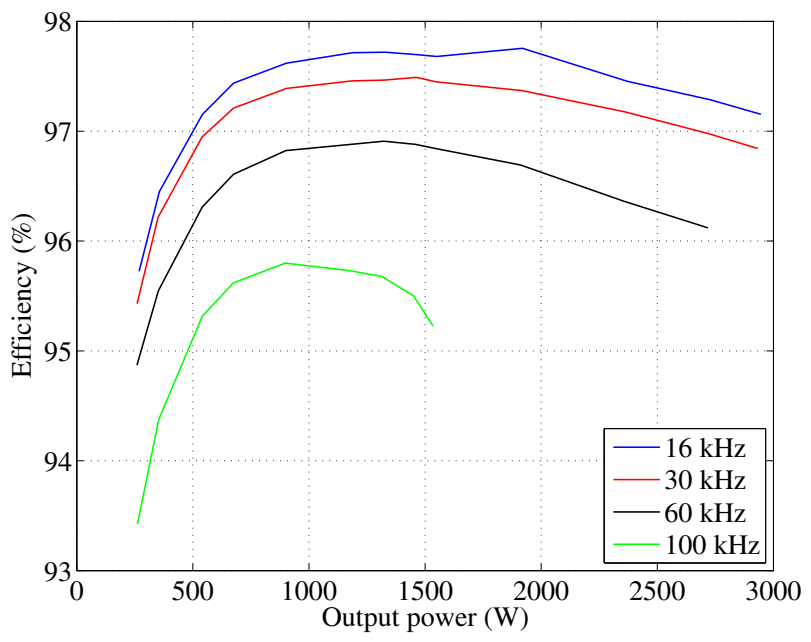

Fig. 9. Measured efficiencies of SiC T-Type inverter for switching frequencies up to $100 \mathrm{kHz}$

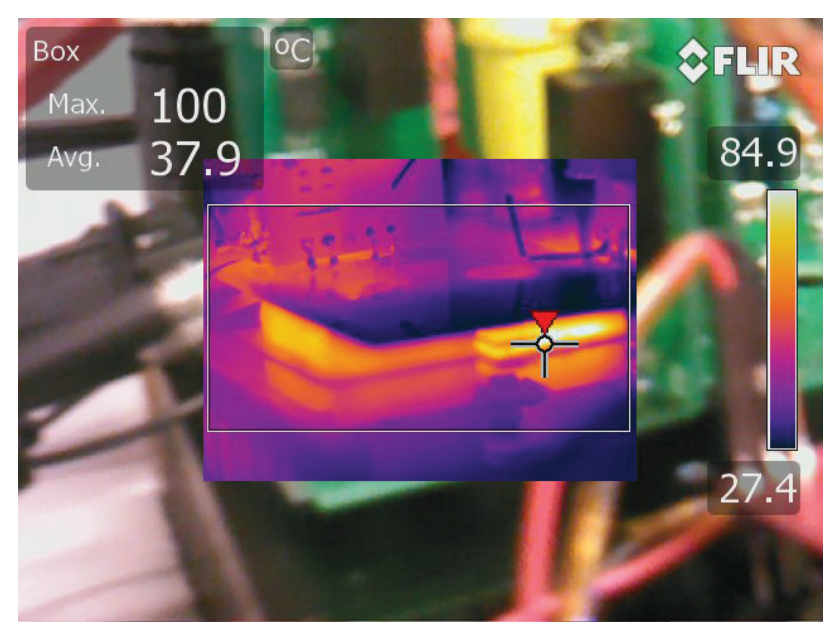

Fig. 10. Case temperature of $600 \mathrm{~V}$ devices in the TO-220 package at a switching frequency of $60 \mathrm{kHz}$ and an output power of $2.7 \mathrm{~kW}$

The case temperature of the TO-220 package is measured to be $100{ }^{\circ} \mathrm{C}$ and is much higher than the case temperature of the SiC MOSFET, as it can be seen in the scale on the right hand side of Fig. 10.

\section{CONCLUSIONS}

In this paper the feasibility of $\mathrm{SiC}$ switching devices on a $3 \mathrm{~kW}$ T-Type inverter topology for PV applications has been investigated. Simulations with regular IGBTs and $\mathrm{SiC}$ MOSFETs have been carried out including a breakdown loss analysis to investigate the loss contribution on the overall efficiency. It is shown that efficiency improvements can be achieved when $\mathrm{SiC}$ MOSFETs are equipped in combination with $\mathrm{SiC}$ diodes. A prototype has been built using the same IGBTs and SiC MOSFETs but regular Si diodes instead of SiC diodes. Efficiency measurements have been done to see how much the reverse recovery current of the Si diodes will affect the overall efficiency. Using $\mathrm{Si}$ diodes instead of $\mathrm{SiC}$ diodes, efficiency improvements could be achieved but not as much as it could be in the simulations 
with $\mathrm{SiC}$ diodes. However, switching frequency could be doubled achieving the similar efficiency curves when IGBTs are used. Switching frequencies were increased up to $100 \mathrm{kHz}$ to see how much efficiency drop one might expect. The limiting factor at increased switching frequencies are the $600 \mathrm{~V}$ devices in a TO-220 package. Using external $\mathrm{SiC}$ diodes in combination with $600 \mathrm{~V}$ IGBTs could furthermore improve efficiencies and enable higher switching frequencies.

\section{REFERENCES}

[1] R. Teichmann and S. Bernet, "A comparison of three-level converters versus two-level converters for low-voltage drives, traction, and utility applications," IEEE Trans. Ind. Appl., vol. 41, no. 3, pp. 855-865, 2005.

[2] P. Alemi and D.-C. Lee, "Power loss comparison in two- and three-level PWM converters," in Power Electronics and ECCE Asia (ICPE \& ECCE), 2011 IEEE 8th International Conference on, 2011, pp. 1452-1457.

[3] M. Schweizer, I. Lizama, T. Friedli, and J. W. Kolar, "Comparison of the chip area usage of 2-level and 3-level voltage source converter topologies," in IECON 2010 - 36th Annual Conference on IEEE Industrial Electronics Society, 2010, pp. 391-396.

[4] L. Ma, T. Kerekes, R. Teodorescu, J. Xinmin, D. Floricau, and M. Liserre, "The high efficiency transformer-less PV inverter topologies derived from npc topology," in Power Electronics and Applications, 2009. EPE '09. 13th European Conference on, 2009, pp. 1-10.

[5] J. Pinne, A. Gruber, K. Rigbers, E. Sawadski, and T. Napierala, "Optimization and comparison of two three-phase inverter topologies using analytic behavioural and loss models," in Energy Conversion Congress and Exposition (ECCE), 2012 IEEE, 2012, pp. 4396-4403.

[6] M. Oestling, R. Ghandi, and C.-M. Zetterling, "SiC power devices - present status, applications and future perspective," in Power Semiconductor Devices and ICs (ISPSD), 2011 IEEE 23rd International Symposium on, 2011, pp. 10-15.

[7] Y. Gao, Q. Huang, S. Krishnaswami, J. Richmond, and A. K Agarwal, "Comparison of static and switching characteristics of 1200v 4H-SiC BJT and 1200v si-IGBT," in Industry Applications Conference, 2006. 41st IAS Annual Meeting. Conference Record of the 2006 IEEE, vol. 1, 2006, pp. 325-329.

[8] D. De, A. Castellazzi, A. Solomon, A. Trentin, M. Minami, and T. Hikihara, "An all SiC MOSFET high performance PV converter cell," in Power Electronics and Applications (EPE), 2013 15th European Conference on, 2013, pp. 1-10. 